\title{
O USO DA MADEIRA NAS REDUÇÕES JESUÍTICO-GUARANI DO RIO GRANDE DO SUL. 9 - PILAR DO COLÉGIO DE SÃO MIGUEL ARCANJO ${ }^{1}$
}

\author{
JOSÉ NEWTON CARDOSO MARCHIORI² MARIA CRISTINA SCHULZE-HOFER ${ }^{3}$
}

\section{RESUMO}

A madeira de um pilar do Colégio de São Miguel Arcanjo (São Miguel das Missões, RS - Brasil) foi anatomicamente identificada como Handroanthus pulcherrimus (Sandw.) S. Grose, o ipê-amarelo da Floresta Estacional no Rio Grande do Sul.

Palavras-chave: Anatomia da Madeira, Handroanthus pulcherrimus, Tabebuia pulcherrima, Bignoniaceae, Missões Jesuíticas, Rio Grande do Sul.

\section{SUMMARY}

[Wood utilization in the Jesuitic-Guarani Missions from Rio Grande do Sul state, Brazil. 9 - Remaining pillar from Saint Michel's College].

The wood of a remaining pillar from Saint Michel Archangel's College (São Miguel das Missões, Rio Grande do Sul state - Brazil) was identified under microscope as Handroanthus pulcherrimus (Sandw.) S. Grose, the "yellow ipê" from the Seasonal Forest of Rio Grande do Sul state, Brazil.

Key words: Wood Anatomy, Handroanthus pulcherrimus, Tabebuia pulcherrima, Bignoniaceae, Jesuitic Missions, Rio Grande do Sul state - Brazil.

\section{INTRODUÇÃO}

As ruínas de São Miguel Arcanjo testemunham o apogeu da arquitetura Jesuítico-Guarani em terras do atual Rio Grande do Sul. Situada no núcleo urbano de São Miguel das Missões, este reconhecido Patrimônio da Humanidade compõe, juntamente com o Museu das Missões, um dos principais focos do turismo históricocultural no Estado.

Com cerne parcialmente desintegrado e sinais de podridão parda, o pilar do Colégio de São Miguel Arcanjo (Figura 1A) atualmente se encontra sob cobertura na ruína estabilizada,

1 Recebido em 20-4-2009 e aceito para publicação em 30-10-2009.

2 Engenheiro Florestal, Dr., Professor Titular do Departamento de Ciências Florestais, Universidade Federal de Santa Maria, RS. Bolsista de Produtividade em Pesquisa, CNPq - Brasil. balduinia@mail.ufsm.br

Arquiteta e Urbanista. Dra., IPHAN - Instituto do Patrimônio Histórico e Artístico Nacional. schulzehofer@gmx.de sendo um dos poucos vestígios construtivos em madeira, remanescente dessa Redução. O presente estudo, ao identificar anatomicamente a espécie de madeira, também visa a contribuir para o conhecimento das técnicas construtivas neste singular período da história regional.

\section{MATERIAL E MÉTODOS}

Coletadas em junho de 2005, as amostras de madeira utilizadas no presente estudo (Figura 1B, C) foram extraídas do fragmento remanescente do pilar. Registradas em fichário, fotografadas e acondicionadas em envelope, com identificação, as amostras foram enviadas ao Laboratório de Anatomia da Madeira do Instituto Nacional de Pesquisas da Madeira, em Lohbrügge - Hamburgo (Alemanha), onde foram realizados os trabalhos de microtécnica e fotomicrografia. Os autores agradecem à senhora Eda John, pela colaboração nestas tarefas.

Das amostras de madeira foram preparados corpos-de-prova, orientados para a obtenção de cortes anatômicos nos planos transversal, lon- 

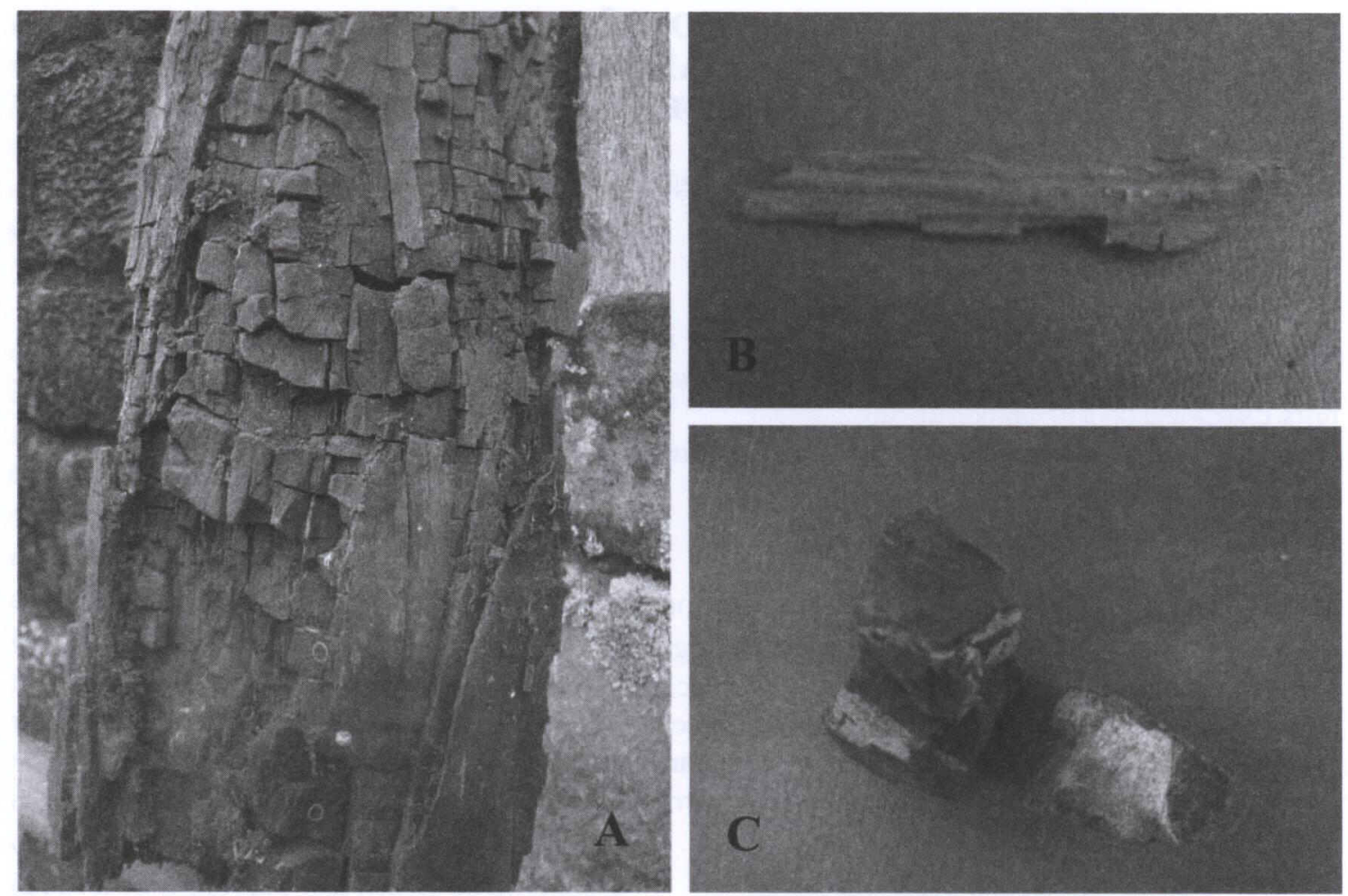

FIGURA 1 - Pilar do colégio de São Miguel Arcanjo. A - Vista do pilar, com sinais evidentes de podridão parda. B, C - Amostras coletadas para estudos anatômicos.

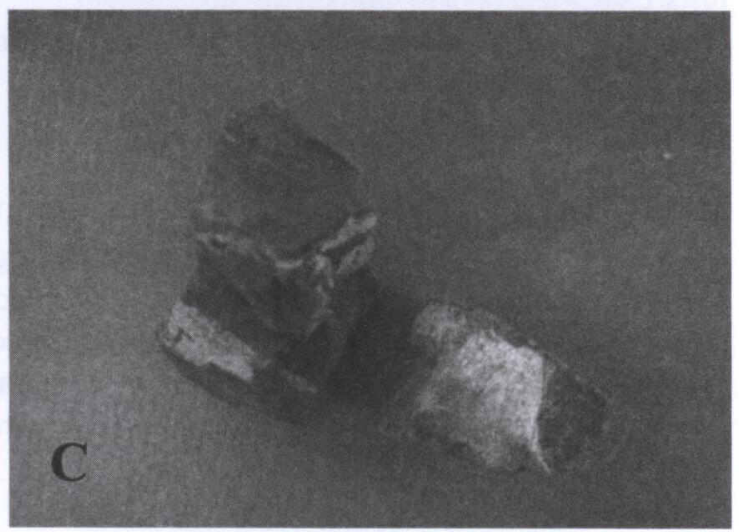

gitudinal radial e longitudinal tangencial. Os corpos-de-prova foram fervidos em água, com vistas ao amolecimento e expulsão completa do ar, incluídos em PEG 2000 e seccionados em micrótomo de deslizamento (modelo American Optical), regulado para a obtenção de cortes anatômicos com espessura nominal de $20 \mu \mathrm{m}$.

Os cortes radiais foram tratados, em parte, com hipoclorito de sódio, com vistas a salientar eventual presença de cristais. As fotomicrografias de Figura 2 foram tomadas com câmera Olympus AX, em diferentes aumentos.

\section{DESCRIÇÃO ANATÔMICA}

Anéis de crescimento não visíveis na lâmina anatômica (Figura 2A). Porosidade difusa (Figura 2A). Poros muito numerosos, de $40-$ $70 \mathrm{~mm}$ de diâmetro, ovais ou arredondados e geralmente solitários, menos comumente em múltiplos radiais de $2-3$ e em múltiplos racemiformes de até 5 unidades (Figura 2A, B). Madeira de estratificação completa, regular, incluindo elementos vasculares, parênquima axial, raios e fibras (Figura 2E, F).

Elementos vasculares tendentes a retilíneos (Figura 2C, E, F), com placa de perfuração simples e abundante conteúdo amarelado na cavidade celular. Pontoações intervasculares alternas, não ornamentadas, de 12 a $14 \mu \mathrm{m}$ de diâmetro, com aréola circular e abertura lenticular inclusa. Espessamentos espiralados, ausentes.

Parênquima paratraqueal escassamente vasicêntrico e confluente, compondo segmentos tangenciais (Figura 2A, B). Séries parenquimáticas, geralmente de 2 células (Figura 2F).

Raios com freqüência de 5 a 10 por mm (Figura 2E), compostos inteiramente de células procumbentes (Figura 2D). Raios com menos 

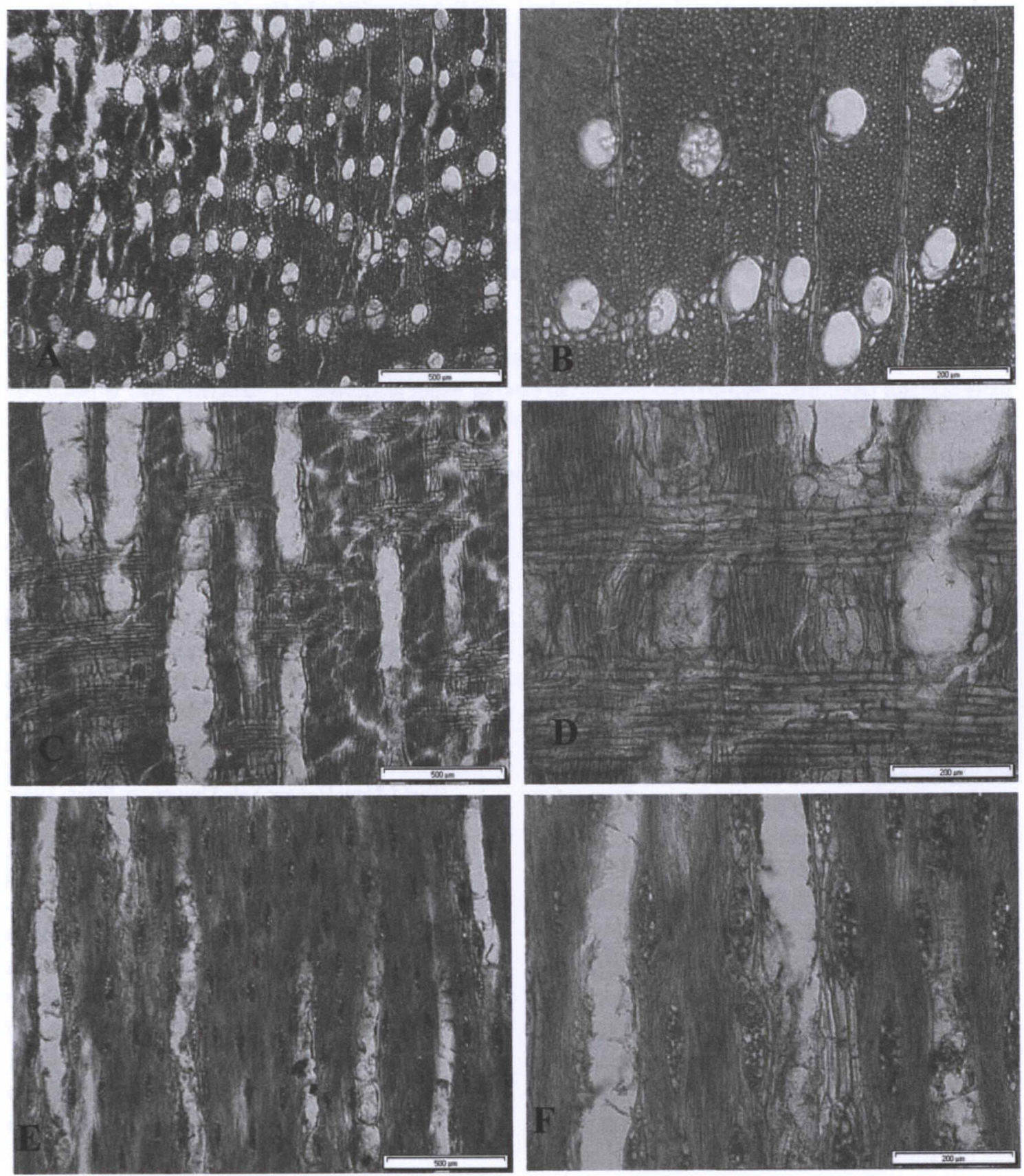

FIGURA 2 - Fotomicrografias da madeira do pilar do colégio de São Miguel Arcanjo. A - Seção transversal, mostrando porosidade difusa, poros ovais muito numerosos e parênquima escassamente vasicêntrico e confluente, compondo segmentos tangenciais. B - Mesmos aspectos da imagem anterior, com maior aumento. C - Linhas vasculares retilíneas e raios homogêneos, em seção radial. D - Raios compostos inteiramente de células procumbentes, em seção radial. E - Linhas vasculares retilíneas e madeira de estratificação completa, em seção tangencial. F - Estratificação completa, fibras de paredes espessas a muito espessas e parênquima axial com 2 células por série, em seção tangencial. 
de 10 células de altura e geralmente bisseriados, menos comumente uni e trisseriados (Figura 2E, F).

Fibras libriformes de paredes espessas a muito espessas (Figura 2A, B).

\section{ANÁLISE ANATÔMICA E DISCUSSÃO}

As pontoações não ornamentadas, a porosidade difusa, a ausência de espessamentos espiralados e os raios estreitos e baixos, indicam o material em estudo como pertencente à família Bignoniaceae, segundo chave dicotômica para madeiras americanas com estrutura estratificada (Record, 1943).

A presença de raios finos e baixos, com menos de 10 células de altura e geralmente 2 células de largura (menos comumente uni e trisseriados), o parênquima paratraqueal, a porosidade difusa, e o abundante conteúdo amarelado nos vasos, inserem a amostra no grupo "Lapacho" do gênero Tabebuia, segundo Record \& Hess (1940). Composto de numerosas espécies - e com ampla área de distribuição geográfica - o referido grupo distingue-se das demais seções do gênero pela cor castanho-esverdeada da madeira, bem como pela presença abundante de lapachol em vasos do cerne (Record \& Hess, 1943).

O exame comparativo dos três cortes anatômicos com exemplares da laminoteca do Departamento de Ciências Florestais da UFSM permite identificar o material como Tabebuia pulcherrima Sandw., binômio atualmente reduzido à sinonímia de Handroanthus pulcherrimus (Sandw.) S. Grose. Trata-se de um ipê-amarelo nativo na Floresta Estacional do Alto Uruguai, bem como no leste do Paraguai e na Selva Misionera da Argentina (Zapater et al., 2009). Sob microscópio, esta espécie distingue-se do ipê-roxo (Handroanthus heptaphyllus) pela predominância de raios bisseriados, com escassos trisseriados, pelos vasos com diâmetro inferior a $80 \mu \mathrm{m}$ e pelo parênquima mais abundante, compondo segmentos tangenciais confluentes e conspícuos. Resta comentar que a madeira desta espécie de ipê foi descrita, sob o ponto de vista anatômico, por Marchiori (2009).

\section{REFERÊNCIAS BIBLIOGRÁFICAS}

MARCHIORI, J.N.C. Estudo anatômico da madeira de Handroanthus pulcherrimus (Sandwith) S. Grose. Balduinia, Santa Maria, n. 19, p. 10 13, 2009.

RECORD, S.J. Woods of storied structure. Tropical Woods, n. 76, p. 32-47, 1943.

RECORD, S.J.; HESS, R.W. American timbers of the family Bignoniaceae. Tropical Woods, n. 63, p. 9-38, 1940 .

RECORD, S.J.; HESS, R.W. Timbers of the New World. New Haven: Yale University Press, 1943. $640 \mathrm{p}$.

ZAPATER, M.A.; CALIFANO, L.M.; CASTILLO, E.M. del; QUIROGA, M.A.; LOZANO, E.C. Las especies nativas y exóticas de Tabebuia y Handroanthus (Tecomeae, Bignoniaceae) en Argentina. Darwiniana, v. 47, n. 1, p. 185-220, 2009. 